\title{
AN UNUSUAL CONDITION OF THE POSTERIOR SURFACE OF THE CORNEA (POSTERIOR HERPES OF THE CORNEA)
}

\author{
BY \\ L. STAZ \\ JOHANNESBURG, SOUTH AFRICA
}

Mr. M. D., when first seen in January, 1932, was aged 18 years. $\mathrm{He}$ had had glasses from an optician two years previously. $\mathrm{He}$ complained of a pain behind the left eye of about two months' duration, and inability to shoot. The latter complaint, no doubt, was advanced in order to obtain a certificate of exemption from military service.

On examination, the patient was found to be a well-built youth with a bad complexion. His entire face was badly covered with acne vulgaris and comedones. His vision was-

$$
\begin{gathered}
\text { Right }=6 / 9 \text { (ii) Left }=6 / 9 \\
\text { Right with }+0.75 \text { D. sph. }=6 / 6 \\
+0.5 \text { D. cyl. Axis } 115^{\circ} \\
\text { Left with }+0.75 \text { D. sph. }=6 / 6 \text { most. }
\end{gathered}
$$

During retinoscopy one was struck by a peculiar reflex in the beam of light, and further examination with the loupe, and then with the corneal microscope showed this to be caused by an opacity on the posterior surface of both corneae.

The opacities were well seen with the Zeiss Corneal Microscope Ocular No. 2 and Objective A2 giving a magnification of $23 \mathrm{X}$.

In the right cornea (Fig. 1a), in its upper half, was found a longitudinal grey-white area, and in an irregular row in the centre of this band were a few clear circular holes. The band was located in the position of the corneal endothelium and the clear areas caused the slit-lamp beam to bulge into the anterior chamber. They looked like small vesicles, but the posterior surface could not be seen, and one was left with the impression that the clear areas were ruptured vesicles. There was a similar condition in the lower half of the left cornea.

In February, 1933, there was an extension of the condition in both eyes (Fig. $1 b$ and $2 b$ ).

In May, 1933, and January, 1934, no change was noted.

On August 20th, 1934, the condition was as follows :-

In the right eye the opacity stretched from above the centre of the cornea to " 9 o'clock" on the edge of the semi-dilated pupil (Fig. 2). The grey area was of uneven thickness, being denser at the temporal end, and the clear areas were punched out, with raised edges. It appeared as if the layer of endothelial cells had become curled forward and folded over. 


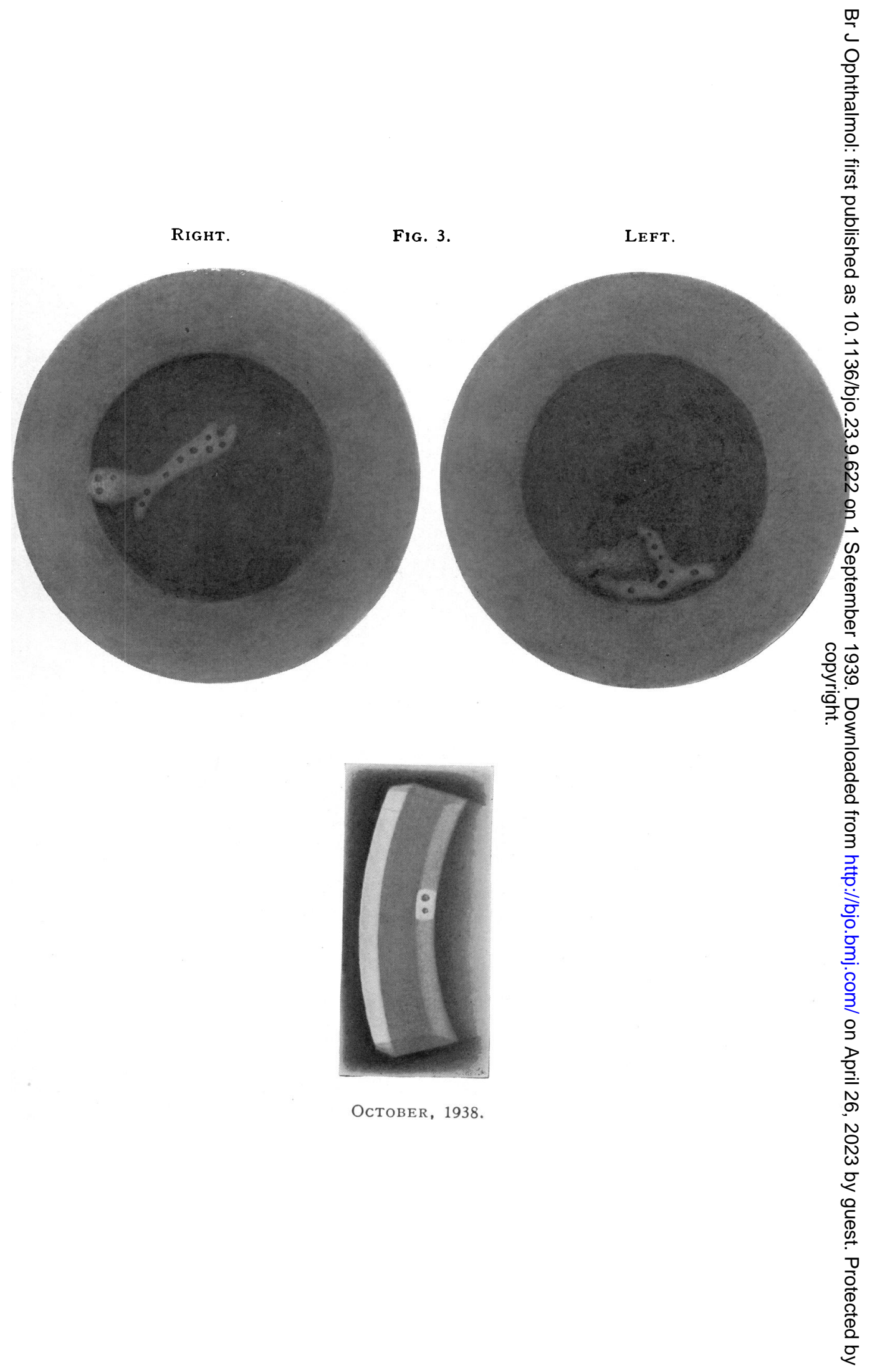


Fig. 1. Right Eye.

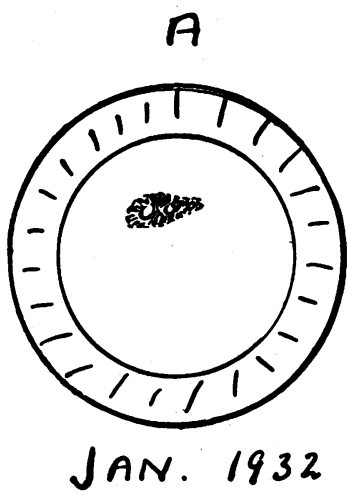

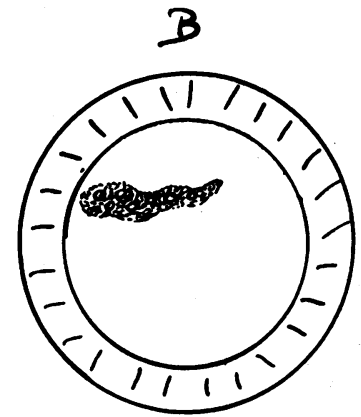

FEB. 1933

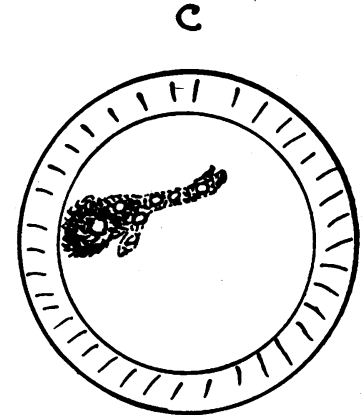

AUG. 1834

Magnification $\times 23$.

Fig. 2. LEFT EyE.

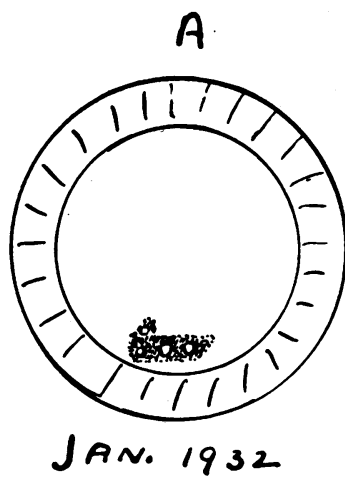

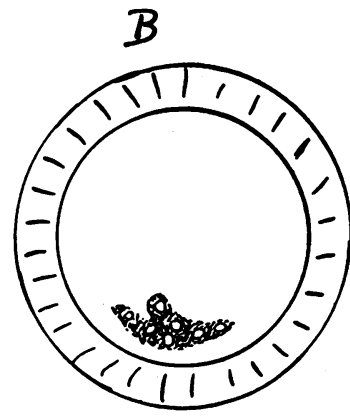

FEB. 1933

Magnification $\times 23$.

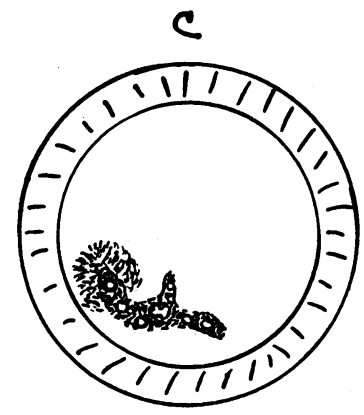

Auc. 1934

In the left eye the condition was situated at " 6 o'clock" on the edge of the iris. The nasal end was surrounded by a nebulous haze containing no holes.

When examined in the zone of specular reflection, the changes were found to have occurred in the endothelium. The corneae were slightly thickened.

Vision without glasses-Right $=6 / 9$ partly. Left $=6 / 9$. His complexion was as bad as at the original examination. There had never been pain or inflammation in the eyes. He was not subject to the common cold and had never had herpes labialis.

In March, 1936, examination revealed no change in the condition with the exception that in the left eye, the clear gaps were beginning to coalesce in some cases and caused large gaps in the endothelial layer.

In October, 1938, the condition was still as shown in Fig. 3 (drawn from rough diagrams). There was now a suspicion of 
early interstitial changes in the right cornea, superficial to the deep area. Vision unaided was-Right $=6 / 9$. Left $=6 / 6$. In the right eye, the opacity was just visible to the naked eye, on careful inspection.

In the literature the following paragraphs appear in Koby (1930): "Under the name of posterior herpes of the cornea, Schnyder describes a curious condition, of which he has seen three cases in several years. It occurs in people suffering from recurrent attacks of herpes labialis, which seem to become gradually less severe. The patient complains of pain in the eye, although there is no appreciable injection. By focal light, there is seen on the posterior surface of the cornea a more or less rounded superficial opacity, like a thin veil containing a few very stable bullae having a bright reflex and measuring from 0.05 to $0.1 \mathrm{~mm}$. in diameter. If these changes are focussed in the posterior zone of specular reflection, it is found that the bright yellow pattern of the endothelial cells is marked by dark holes in the situation of the bullae. The outlines of the cells cannot be seen in the region of the bullae."

"The superficial opacity surrounding the bullae, their visibility in focal light, and the coincidence of herpes labialis are sufficient to differentiate these changes from Hassal-Henle bodies, which can be seen only in the zone of specular reflection. Kneusel has seen similar vesicles on the posterior surface of the cornea, in four patients who had no herpes. There were usually half a dozen vesicles from 30 to 100 microns in diameter surrounded by a slight haze."

Peter (1932) recognises three types of endothelial dystrophy :-

(1) that observed after iridocyclitis,

(2) following trauma,

(3) true dystrophy of the endothelium.

He states that all cases should be studied by direct illumination along the line of specular reflection. In type 1 are seen a varying number of black pigmented spots lying upon endothelial cells of blurred outline and even surface. In type 2 the changes are usually limited to the region affected. The endothelial mosaic varies in level, oedema is marked and evanescent black spots are seen. The epithelium is usually involved. In type 3 the condition is permanent and bilateral and begins in the centre of the cornea. It can only be recognised in its incipiency by the slitlamp when large round black non-reflecting areas appear. Vision remains perfect. In the second stage the lesion advances towards the periphery and the endothelial surface takes on the appearance of beaten silver, the hexagonal cells become fewer and a burnished silver network surrounding black non-reflecting areas can be seen everywhere. Vision falls and the fundus is seen with difficulty. 
Dystrophy was found in Peter's series in association with senile and nuclear cataract being usually in patients over fifty years of age. The disease constitutes a serious complication in operative conditions probably due to loss of vitality. There is no tendency to regeneration.

Basil Graves (1924) described his observations in twenty-two cases of a bilateral chronic affection of the corneal endothelium of elderly persons. His cases appear to be cases of " cornea guttata " and differ from that now reported.

Goar (1934) summarises his paper on dystrophy of the corneal endothelium as follows:--

" (1) Dystrophy of the corneal endothelium or cornea guttata (Vogt) is a clinical entity occurring in some degree in about six per cent. of people or persons above twenty years of age.

" (2) It usualiy begins in the fourth or fifth decade, and is three times as common in women as in men.

" (3) It is a chronic slowly progressive disease of the corneal endothelium, resulting in irregular thickenings and excrescences of Descemet's membrane. These excrescences are usually directed posteriorly and have identical staining properties with the membranes from which they are derived.

" (4) Advanced cases of this disease reduce the vision very materially, and these may be recognised by oblique illumination and by the ophthalmoscope. Early cases may be diagnosed only by biomicroscopy.

“" (5) Epithelial dystrophy is often found in advanced cases, and it may be the late stage of the process which is represented by endothelial dystrophy as an earlier stage."

In the discussion, various speakers emphasised that in the early stages of this condition of cornea guttata centralis, the corneal microscope is necessary for its detection, and also that it is associated with senile and pre-senile changes. The case which is now being reported occurs in a young man, and the details are easily visible with a loupe and focal illumination.

Freudenthal (1933) describes " Two cases of familial endothelial dystrophy of the cornea with general degenerative changes." In the anterior corneal lamellae delicate nebulae were seen. The posterior surface of the cornea was very rough and in many spots the endothelium was greatly swollen while in narrow contiguous zones the endothelium was vesicular. With lower magnification, these areas looked like sharply circumscribed deposits on Descemet's membrane of a peculiar yellowish white colour. These lesions were uniformly distributed over both corneae. Visual acuity was reduced. The son had myopic astigmatism, divergent strabismus, and general debility, probably resulting from a thyroid-hypophyseal dysfunction. A younger son was 
normal generally and had normal eyes. The wife had dementia praecox, his sister a syphilitic lesion of the cornea and her son normal cornea and hyperthroidism.

Juler (1934) presented a man, aged 39 years, with a rupture of Descemet's membrane following contusion as a result of a war injury. The left cornea showed a sinuous line on its posterior surface; it did not reach the limbus. From this, a shelf projected back into the anterior chamber, evidently formed by Descemet's membrane. There was a thinning of the posterior layer of the cornea corresponding to the previous bed of the shelf. In two places there were seen to be some rounded globules growing from the posterior corneal surface in the shelf area.

Doggart (1933) who in recent years has published a good deal of work on the corneal complication of acne rosacea, and other skin conditions, makes no mention of any similar case.

Sholi, of Fuknoka, Japan (1931), has described a pigmented network of the posterior surface of the cornea in a patient 64 years of age, who had a cataract extraction. He concludes that $i t$ is the result of an anomaly in the early stage of development of the eyeball.

Cases of Groenouw's nodular degeneration of the cornea have been reported repeatedly-Judd (1933), Treacher Collins (1902), and Marcus Gunn (1902), reported a case showing deposits on the back of the cornea, following iridocyclitis. They were few in number and worm-like in appearance.

The case reported above is one of "Posterior Herpes of the Cornea "-Kneusel's sub-division, as described in Koby (1930) "Slit-lamp Microscopy of the Living Eye," or the earliest stage of dystrophy of the corneal endothelium.

The patient reports for examination whenever requested to do so. In 1937 he married and now has a child. It is hoped that both he and his off-spring will remain under observation for many years.

\section{REFERENCES}

Treacher Collins.-Trans. Ophthal. Soc. U.K., p. 148, 1902.

Doggart.-Ocular complications of Acne Rosacea. Brit. Jl. Ophthal., Vol. XV, p. 446, August, 1931.

Brit. Jl. Ophthal., Vol. XVII, pp. 65, 385, 513, 1933.

Freudenthal.-Amer. Jl. Ophthal., p. 172, 1933. Abstract by Haessler.

GoAR, E. L.-Dystrophy of the Corneal Endothelium. Amer. Jl. Ophthal., Vol. XVII, No. 3, p 215, March, 1934.

Graves, Basil. - A Bilateral Chronic Affection of the Corneal Endothelium of Elderly Persons - Report to the Lang Clinical Research Committee, R.L.O. Hospital. Brit. Jl. Ophthal., p. 503, November, 1924.

GunN, Marcus.-Trans. Ophthal. Soc. U.K., p. 150, 1902.

JUDD, J. H.- Nodular Degeneration of the Cornea. Amer. Jl. Ophthal., Vol. XVI, p. 310, April, 1933. (Abstract in Year Book of Eyes, 1933.)

Juler, F. A.- Rupture of Descemet's Membrane from a Contusion. Proc. Roy. Soc. of Med., London, November 24, 1934.

Кову.-Slit-Lamp Microscopy of the Living Eye. Second Edition (English), pp. 109 and $165,1930$.

Peter, L.-Amer. Jl. Ophthal., p. 382, 1932. Abstract by M. H. Post from Arch. of Ophthal., pp. 817.822, 1931.

Sholı.-Brit. Jl. Ophthal., p. 596, 1931. Abstract. 